\title{
Maternal autogenous inactivated virus vaccination boosts the piglet humoral and cell-mediated immunity to PRRSV via transfer of neutralizing antibodies and interferon-gamma producing $B$ cells
}

\author{
Andrew R. Kick ${ }^{1,4}$, Zoe C. Wolfe ${ }^{1}$, Amanda F. Amaral1, Lizette M. Cortes ${ }^{1}$, Glen W. Almond ${ }^{1}$, Elisa \\ Crisci $^{1}$, Phillip C. Gauger ${ }^{2}$, Jeremy Pittman ${ }^{3}$ and Tobias Käser ${ }^{1 *}$ \\ 1 Department of Population Health and Pathobiology, College of Veterinary Medicine, North Carolina \\ State University, Raleigh, NC 27607, USA \\ 2 Veterinary Diagnostic and Production Animal Medicine, Iowa State University, Ames, IA 50011, USA \\ 3 Smithfield Foods, Smithfield, VA 23430, USA \\ 4 Department of Chemistry \& Life Science, United States Military Academy, West Point, NY 10996, USA \\ * Correspondence: tekaeser@ncsu.edu; Tel.: +1-919-513-6352 (T.K.)
}

\begin{abstract}
Maternal-derived immunity is a critical component for survival and success of offspring in pigs to protect from circulating pathogens like Type 2 Porcine Reproductive and Respiratory Syndrome Virus (PRRSV-2). The purpose of this study was to investigate the transfer of anti-PRRSV immunity to piglets from gilts that received modified-live virus (MLV) alone (TRT 0), or in combination with one of two autogenous inactivated vaccines (AIVs, TRT 1+2). Piglets from these gilts were challenged with the autogenous PRRSV-2 strain at two weeks of age and their adaptive immune response (IR) was evaluated until 4 weeks post inoculation (wpi). The systemic humoral and cellular IR was analyzed in the pre-farrow gilts, and in piglets, pre-inoculation, and at 2- and 4wpi. Both AIVs partially protected the piglets with reduced lung pathology and increased weight gain; TRT 1 also lowered piglet viremia best explained by the AIV-induced production of neutralizing antibodies in gilts and their transfer to the piglets. In piglets, pre-inoculation, the main systemic IFN- $\gamma$ producers were CD21 $\alpha^{+}$B cells. From 0 to 4 wpi, the role of these B cells declined and CD4 T cells became the primary systemic IFN- $\gamma$ producers. In lungs, CD8 T cells were the primary and CD4 T cells the secondary IFN- $\gamma$ producers including a novel subset of porcine CD8 $\alpha^{-}$ CCR7- CD4 T cells, potentially terminally differentiated CD4 TEMRA cells. In summary, this study demonstrates that maternal AIV vaccination can improve protection of pre-weaning piglets against PRRSV-2; it shows the importance of transferring neutralizing antibodies to piglets; and it introduces two novel immune cell subsets in pigs - IFN- $\gamma$ producing CD21 $\alpha^{+} \mathrm{B}$ cells and CD8 $\alpha^{-}$ CCR7- CD4 T cells.
\end{abstract}

Keywords: maternal vaccination, autogenous inactivated vaccine, transfer of immunity, humoral immune response, cell-mediated immune response, T cells, PRRSV, swine, IFN- $\gamma$ producing B cells, CD4 TeMra cells

\section{Introduction}

Maternal-derived immunity (MDI) in mammals is an awe-inspiring symphony ("harmonious complexity" - [1]). In this system or symphony, a mother transfers immune protection (temporary and/or enduring) to her offspring either during gestation through the placenta, after birth through mammary secretions, or both [2]: humans receive immunoglobulins during gestation and eventually through mammary secretions [3]; dogs and rodents receive immunoglobulins during gestation and through mammary secretions; and pigs and other livestock only receive immunoglobulins through mammary secretions. As other species, piglets receive this MDI in the form of immunoglobulins, 
immune cells, and other immune-related molecules [4,5]. While immunoglobulins can be received from different sows (=cross-fostering), only biological mothers can successfully transfer immune cells to their offspring [5]; and the quantity of colostrum intake in piglets significantly decreases mortality and improves performance [6]. These immune cells include B cells [7], as well as different T-cell subsets - CD4, CD8 and mainly TCR- $\gamma \delta \mathrm{T}$ cells [8]. These T-cell subsets can then be further distinguished based on their differentiation stage and homing pattern. In pigs, the CD8 $\alpha$ chain is used to differentiate $\mathrm{CD} 8 \alpha$ - naïve from $\mathrm{CD} 8 \alpha^{+}$antigen-experienced or memory CD4 T cells [9-11]. The expression of the chemokine receptor CCR7 further distinguishes CCR7 $7^{+}$lymph node homing from CCR7- peripheral tissue-homing T cells [12]. With a combined CD8 $\alpha / C C R 7$ analysis, we can then distinguish multiple different T-cell subsets: $\mathrm{CD} 8 \alpha-\mathrm{CCR} 7^{+}$naïve $\mathrm{CD} 4 \mathrm{~T}$ cells, $\mathrm{CD} 8 \alpha^{+} \mathrm{CCR} 7^{+}$central memory (Тсм) CD4 T cells, and CD8 $\alpha+C C R 7-$ effector memory (Тем) CD4 T cells; peripheral tissuehoming CCR7- and lymph node homing CCR7 ${ }^{+}$CD8 T cells; and CD8 $\alpha$-CCR7-, CD8 $\alpha^{+}$CCR7-, and CD $8 \alpha^{+}$CCR7+ TCR $-\gamma \delta \mathrm{T}$ cells. While we previously reported that porcine TCR $-\gamma \delta \mathrm{T}$ cells possess an inverse homing pattern compared to their TCR- $\alpha \beta$ counterparts, the specific role of these different subsets has yet to be described [13]. Both, immune cell subsets and antibodies are transferred to the offspring to protect them against various pathogens [4,5].

For decades, the most disastrous pathogen for pigs is the Porcine Reproductive and Respiratory Syndrome Viruses [PRRSV, [14, 15]]. Two main types of PRRSV exist - type 1 and 2 (PRRSV-1\&2); their high diversity and immunosuppressive capacities make PRRSV a problematic disease leading to tremendous economic losses for the swine industry [16]; and so far, while vaccines provide partial protection against PRRSV, they were not able to fully control this disease.

Two main vaccine types are available to protect against PRRSV - modified live virus (MLV) vaccines and inactivated vaccines, mainly autogenous inactivated vaccines (AIVs); but both types face their own challenges: The long time to develop the very immunogenic MLV vaccines makes them usually more heterologous to farm-prevalent PRRSV strains; and while AIVs are directed against these farm-prevalent strains, their inactivated nature makes them generally less immunogenic. These challenges lead to a lack of protection especially in young pigs that can be attributed to three factors: First, the high mutation rate of PRRSV limits heterologous protection, so it reduces MLV vaccine efficacy; second, its immunosuppressive capacity limits weaker vaccines (so rather AIVs) and its delay of the induction of a protective immune response leaves especially young pigs susceptible [17]; and third, our understanding of the immune response to PRRSV especially in piglets is limited. The general understanding of the immune response to PRRSV is nicely reviewed in $[18,19]$.

Mainly based on the extended time to establish vaccine-induced immunity to PRRSV, swine producers often vaccinate gilts and sows to enable transfer of immunity to young piglets. Research on maternal vaccination using a commercial MLV against type PRRSV-1 did not impede vaccination of 2 or 3 week old piglets and it partially protected piglets against heterologous challenge [20]. This vaccination strategy also induced PRRSV-1-specific IgG, IgA, and IFN- $\gamma$ secreting cells in the colostrum and milk of vaccinated sows; and serum anti-PRRSV IgG was detectable through six weeks of age for unvaccinated piglets and remained stable in vaccinated piglets prior to challenge; yet, IFN$\gamma$ secreting cells could not be distinguished from background in pre-weaned piglets [21]. While the use of MLVs is an industry standard, a combined vaccination regimen of an MLV prime and AIV boost vaccination seems promising to overcome each of the downsides of the MLV and AIV vaccines alone.

Therefore, the main goal of this study was to determine not only if but also how maternal vaccination with two different AIV vaccines (TRT 1+2) can boost an industry standard MLV vaccination alone (TRT 0) to better protect the offspring from early PRRSV-2 challenge. To this end, we studied the vaccine-induced humoral and cell-mediated immune (CMI) response in these gilts; and we challenged early weaners from gilts within each of those groups at 2 weeks of age. The systemic and local immune response of those piglets was followed for 2-4 weeks. We show that AIV boost vaccination could improve protection of piglets against PRRSV challenge at 2 weeks of age; and we could also identify the underlying immune mechanisms and characterize the anti-PRRSV 
humoral and CMI response in these young pigs. In addition, we detect two new cell types in pigs: 1) CD8 $\alpha$-CCR7- CD4 T cells that strongly contribute to the IFN- $\gamma$ production in bronchoalveolar lavage (BAL) - potential CD4 TEMRA cells, and 2) a major source of the anti-PRRSV response especially in young piglets - IFN- $\gamma$ producing B cells.

\section{Materials and Methods}

\subsection{Study design, animals, and sample processing.}

The purpose of this study was to evaluate the effect of different maternal PRRSV-2 vaccination series on protective immunity in weaned piglets against PRRSV-2. Prior to the study, a circulating PRRSV-2 strain (restriction fragment length polymorphism (RFLP), 1-7-4) from a North Carolina pork company was isolated and propagated by two independent biological sciences companies; they produced two distinct autogenous vaccines. Both vaccines contained different proprietary components but contained the same inactivated 1-7-4 PRRSV-2 strain. The design of this study is illustrated in Figure 1.

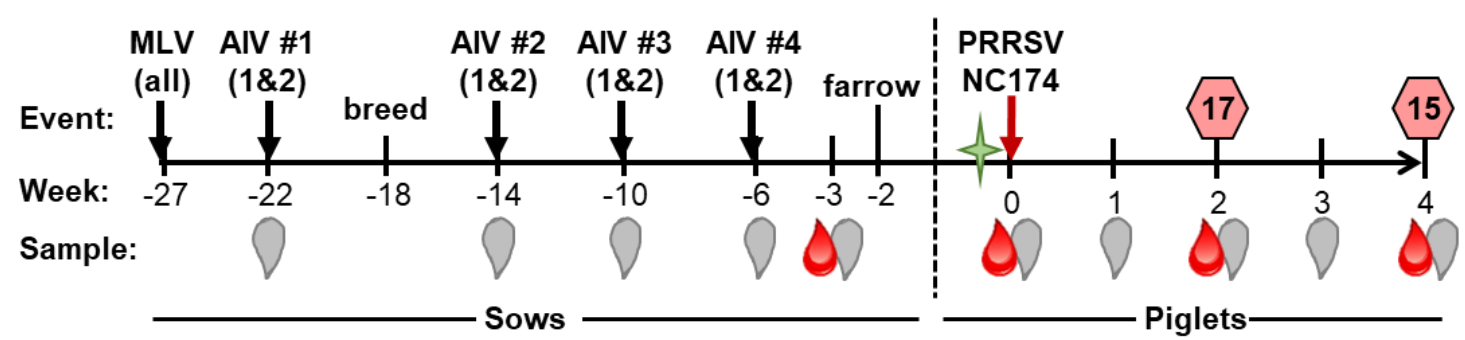

PBMC collection Legend
Serum (+piglet BW/Temp)
$\downarrow$ Vaccination (strain)
$\downarrow$ Wean / transport to LAR
$\downarrow$ Inoculation with strain
17 \# animals sacrificed

Figure 1: Study design: The study included sows that were either vaccinated with a modified live vaccine only (MLV, TRT 0), or a MLV boosted by a series of four vaccinations using one of two autogenous inactivated virus (AIV) vaccines (TRT 1+2). One week before farrowing, blood from sows was collected to assess the systemic humoral and cell-mediated adaptive immune response. Piglets from three high-responding sows within each treatment group (TRT 0,1,2) were included in the second part of the study - the challenge part at the NC State Laboratory Animal Resources (LAR). These piglets were intranasally inoculated with the autogenous PRRSV 1-7-4 strain at two weeks of age (0 weeks post inoculation, wpi). Pigs were also bled as illustrated to assess the immune response to PRRSV; to assess lung pathology and study the local immune response, half of the pigs were sacrificed at 2 wpi and half at 4 wpi.

Both vaccinations were administered intramuscularly in a series of four doses prior to farrowing: In accordance with the North Carolina pork company corporate vaccination schedule, 46 PRRSV-2 negative gilts in a commercial sow farm were vaccinated with the Ingelvac PRRS MLV vaccine (Boehringer Ingelheim Vetmedica $\mathrm{GmbH}$, Germany) nine weeks prior to breeding. Four weeks prior to breeding, blood samples were collected from all gilts for serum and then gilts were allotted into three treatments: TRT 0 (MLV vaccination only); TRT 1 (MLV vaccination +4 doses of autogenous (17-4) inactivated vaccine 1); or TRT 2 (MLV vaccination +4 doses of autogenous (1-7-4) inactivated vaccine 2). Gilts that did not breed were dropped from the study. At 3 weeks before farrowing, blood was collected from pregnant gilts for the isolation of serum and peripheral blood mononuclear cells (PBMC). At this point, five gilts remained in both TRT 0 and TRT 2; nine gilts remained in TRT 1. Three gilts with a high serum fluorescent focus neutralization (FFN) titer and IFN- $\gamma$ response (=highresponding gilts) from each group were selected to provide piglets for the challenge study. At 2 weeks of age ( $=0$ weeks post infection, wpi), four piglets with the most average litter weights were selected for the challenge study and transported to the Biosecurity Level 2 housing facilities of the North Carolina State University (NCSU) Laboratory Animal Resources (LAR) (Raleigh, NC). Here, they were randomly assigned to one of six pens in the same room; two pigs per treatment were housed in each pen (one per gilt). In summary, there were a total of 36 piglets in the study with 12 piglets per treatment selected from 3 gilts each. During the study, four piglets died from causes other than 
necropsy: Three piglets from one sow (TRT 0) died within 30 hours of arrival at LAR and were dropped from the study. Additionally, one pig (TRT 2) was euthanized between week three and four of the study due to high fever $\left(>106^{\circ} \mathrm{F}\right)$ and lack of response to physical stimulation. This pig was included in all analysis through week 3 and its lungs were assessed for pathology. No flow cytometry analysis occurred for this animal at necropsy.

One day after weaning and arrival at NCSU, all piglets were inoculated intranasally with $1 \mathrm{x}$ $105.5 \mathrm{PRRSV}-2$ viral particles (autogenous strain 1-7-4) in $1 \mathrm{ml} 1 \mathrm{X}$ phosphate buffered saline (PBS) (500 $\mu \mathrm{l} /$ nostril), maintained in a supine position for 30 seconds and returned to their pens. Half the animals were sacrificed at 2 wpi and the remaining animals were sacrificed at 4 wpi. At necropsy, BAL, lungs, and tracheobronchial lymph nodes ( $\mathrm{TrBr} \mathrm{LNs}$ ) were collected and processed as previously described [13].

Sampling occurred prior to inoculation ( $0 \mathrm{wpi})$ and then weekly as shown in Figure 1. Serum was collected in SST tubes (BD Biosciences, San Jose, CA, USA) and blood for PBMC isolation was collected in heparin tubes (BD Biosciences). Animal housing was in accordance with the National Institutes of Health guide for research animals. Piglets had unlimited access to water, were fed a transitional weaning diet, then regular diet twice daily, and maintained at $83^{\circ} \mathrm{F}$ with a 12-hour light / dark cycle. The experimental procedures were approved by the NC State University Institutional Animal Care and Use Committee (IACUC) ID\# 17-166A (29 Nov 2017).

\subsection{Virus propagation, titration, and evaluation.}

The PRRSV-2 viral isolate (strain, 1-7-4) was propagated on PRRSV-negative porcine alveolar macrophages (PAMs) in RPMI-1640, 1X with L-glutamine (Corning, Corning, NY, USA) supplemented with $10 \%$ fetal bovine serum (FBS) (VWR, Radnor, PA, USA) and 1X antibioticantimycotic (Corning) (referred to as RPMI-complete) for approximately 30 hours in T-75 flasks (Sarstedt, Nümbrecht, Germany) until a cytopathic effect was observed. Flasks were freeze-thawed one time and the supernatant was spun at $2200 \mathrm{~g}$ at $4{ }^{\circ} \mathrm{C}$ for $10 \mathrm{~min}$. To concentrate the virus, the supernatant was then transferred to $36 \mathrm{~mL}$ Nalgene centrifuge tubes (Thermo Fisher Scientific, Rochester, NY, USA) and spun in a Sorvall $100 \mathrm{~S}$ Ultracentrifuge (Sorvall, Thermo Fisher Scientific), Newtown, CT, USA) at $73,000 \mathrm{~g}$ at $4{ }^{\circ} \mathrm{C}$ for $2 \mathrm{~h}$. The supernatant was discarded, and the pellet was resuspended in media (RPMI complete) and stored in $100 \mu \mathrm{L}$ aliquots at $-80^{\circ} \mathrm{C}$. The TCID 50 titers of viral stock solutions were determined utilizing PAMs as previously described (Spearman-Karber TCID50 method according to the OIE manual of diagnostic tests (OIE, "Chapter 2.8.7 Porcine Reproductive and Respiratory Syndrome," Terr. Man., no. May 2015, 2015).

\subsection{Viremia.}

Isolated serum was analyzed by the North Carolina pork company's diagnostic laboratory using Real-Time - Quantitative polymerase chain reaction (qPCR) with a 5X MagMAX pathogen RNA/DNA kit (Thermo Fisher Scientific) and VetMAX PRRSV qPCR kit (Thermo Fisher Scientific).

Vaccinated gilt serum was PRRSV-negative (qPCR) at farrowing as determined by Iowa State University Veterinary Diagnostic Laboratory (ISU VDL, Ames, IA). The $\Delta \mathrm{Ct}$ values were calculated by subtracting the $C t$ value of a sample from the $C t$ value considered as PRRSV-negative $\left(\mathrm{Ct}_{\text {neg }}=37\right)$ for PRRSV: $\Delta \mathrm{Ct}=37-\mathrm{Ct}$.

\subsection{Neutralizing antibody validation and determination of positive samples.}

Serum samples from gilts and piglets were shipped to South Dakota State University Animal Research and Diagnostic Laboratory (Brookings, SD) who completed PRRSV-2 NA determination utilizing FFN and the 1-7-4 inoculation strain. A positive result is the highest serum dilution with a $90 \%$ or higher reduction in the number of fluorescent focus forming units [22].

\subsection{Necropsy procedures, scoring, and tissue cell isolations}

At necropsy (2 or $4 \mathrm{wpi})$, animals were sacrificed using lethal injection of Euthasol $(390 \mathrm{mg} / \mathrm{ml}$ pentobarbital, $50 \mathrm{mg}$ phenytoin/ml). Then, the lungs, thymus, and TrBr LNs were harvested. For the lungs, dorsal and ventral photos were taken; lungs were flushed with 1X PBS to collect the bronchial alveolar lavage (BAL); and five total samples were taken for histology: one each from the right and left caudal lobes, right and left middle lobes and then one from the accessory lobe. Histology samples 
were fixed in Formaldehyde/Zn fixative (Electron Microscopy Sciences, Hatfield, PA) for 24 hours and then transferred to $70 \%$ ethanol. The NCSU Histopathology lab performed hematoxylin and eosin (H\&E) staining and slide preparation of the histology samples. Slides (histology) and lung photos (gross pathology) were shipped to ISU VDL and scored by a certified pathologist who was blinded to treatments and necropsy dates; lung lesion and interstitial pneumonia scoring was performed as previously described [23]. For all collected tissues (lungs, thymus, and TrBr LNs), the tissue was cut into small pieces and pressed through stainless steel round drain strainers (Grainger, Lake Forest, IL) into $50 \mathrm{ml}$ tubes with ice-cold PBS to elute single cell suspensions. Fibrous clumps were filtered with $40 \mu \mathrm{m}$ filters (BD Biosciences).

\subsection{Peripheral blood isolation, viral stimulation, and IFN- $\gamma$ FCM staining / analysis.}

PBMC isolation was performed using Ficoll-Paque density centrifugation (GE Healthcare, Uppsala, Sweden) and SepMate-50 ml tubes (STEMCELL Technologies, Vancouver, Canada) in accordance with the manufacturer's protocol. PBMC and single cells suspension cell counts were completed on a CASY cell counting system (Schärfe System, Germany). For the IFN- $\gamma$ production assay, $5 \times 10^{5}$ PBMCs and lymphocytes from lungs, and $\mathrm{TrBr}$ LNs were plated in eight replicates in a 96-well round-bottom plate (Corning) in $100 \mu \mathrm{l}$ RPMI-complete and rested overnight in an incubator at $37^{\circ} \mathrm{C}$ and $5 \% \mathrm{CO}_{2}$. The next morning $100 \mu \mathrm{l}$ of RPMI-complete containing PRRSV strain 1-7-4 (MOI $=0.1$ ) was added to each well; plates were returned to the incubator for 24 hours of viral stimulation. For the last $4 \mathrm{~h}$ of culture, monensin $(5 \mu \mathrm{g} / \mathrm{mL}$, Alfa Aesar) was added to block IFN- $\gamma$ release from the cells. Upon completion of the 24 hour incubation, the replicates were pooled and stained as stated in Table 1; on average 276,756 single living lymphocytes (SLLs) were recorded on a Cytoflex using the CytExpert software (Beckman Coulter). Data analysis was performed with FlowJo version 10.6.1 (FLOWJO LLC). Gating hierarchy for the analysis of the IFN- $\gamma$ response is shown in Figures 4 and 5 for PBMC and in Supplementary Figure 1 and Figure 7 for BAL, lung tissue, and TrBr LNs.

Table 1. Flow cytometry antibody staining panel

\begin{tabular}{|c|c|c|c|c|c|c|}
\hline Antigen & Clone & Isotype & Fluorochrome & $\begin{array}{l}\text { Labeling } \\
\text { strategy }\end{array}$ & $\begin{array}{c}\text { Primary } \\
\text { Ab source }\end{array}$ & 2nd Ab source \\
\hline CD3 & PPT3 & IgG1 & FITC & $\begin{array}{c}\text { Directly } \\
\text { conjugated }\end{array}$ & $\begin{array}{l}\text { Southern } \\
\text { Biotech }\end{array}$ & - \\
\hline $\mathrm{CD} 4$ & $74-12-4$ & IgG2b & $\begin{array}{c}\text { Brilliant } \\
\text { Violet } 480\end{array}$ & $\begin{array}{l}\text { Secondary } \\
\text { antibody }\end{array}$ & $\begin{array}{c}\text { BEI } \\
\text { Resources }\end{array}$ & $\begin{array}{l}\text { Jackson } \\
\text { Immunoresearch }\end{array}$ \\
\hline $\mathrm{CD} 8 \alpha$ & $76-2-11$ & $\operatorname{IgG} 2 \mathrm{a}$ & $\begin{array}{c}\text { Brilliant } \\
\text { Violet } 421\end{array}$ & $\begin{array}{l}\text { Secondary } \\
\text { antibody }\end{array}$ & $\begin{array}{c}\text { BEI } \\
\text { Resources }\end{array}$ & $\begin{array}{l}\text { Jackson } \\
\text { Immunoresearch }\end{array}$ \\
\hline $\mathrm{CD} 21 \alpha$ & $\begin{array}{c}\text { BB6- } \\
11 C 9.6\end{array}$ & IgG1 & $\begin{array}{c}\text { Brilliant } \\
\text { Violet } 605\end{array}$ & $\begin{array}{l}\text { Biotin- } \\
\text { streptavidin }\end{array}$ & Novus Bio & Biolegend \\
\hline TCR- $\gamma \delta$ & PGBL22A & IgG1 & $\begin{array}{l}\text { Alexa Fluor } \\
\quad 647\end{array}$ & $\begin{array}{c}\text { Directly } \\
\text { conjugated }\end{array}$ & Kingfisher & Invitrogen \\
\hline CCR7 & 3D12 & rIgG2a & $\begin{array}{l}\text { Brilliant Blue } \\
\quad 700\end{array}$ & $\begin{array}{c}\text { Directly } \\
\text { conjugated }\end{array}$ & $\begin{array}{c}\text { BD } \\
\text { Biosciences }\end{array}$ & - \\
\hline IFN- $\gamma$ & P2G10 & IgG1 & PE & $\begin{array}{c}\text { Directly } \\
\text { conjugated }\end{array}$ & $\begin{array}{c}\text { BD } \\
\text { Biosciences }\end{array}$ & - \\
\hline $\begin{array}{l}\text { Live / } \\
\text { Dead } \\
\end{array}$ & - & - & $\begin{array}{l}\text { Near Infra- } \\
\text { red } \\
\end{array}$ & - & Invitrogen & - \\
\hline
\end{tabular}

\subsection{Statistical analysis}

Statistical analyses were performed using Graphpad Prism 8 (Graphpad Software, San Diego, CA). Data with a full data set were analyzed by either two-way (throughout the study) or one-way (at necropsy) ANOVAs. Data with missing data points (mainly due to necropsy of $50 \%$ of the pigs at 2 wpi) were analyzed by a mixed-effects model (REML). All multiple comparisons were performed with Dunnett's multiple comparison test. Data illustration was performed using violin plots showing the distribution, individual points, median (as applicable, dashed black line), and $25^{\text {th }} / 7^{\text {th }}$ intervals 
(as applicable, colored line). Correlation analysis between sow and piglet $\mathrm{nAb}$ levels were performed using Pearson correlation coefficients and a two-tailed 95\% confidence interval.

\section{Results}

\subsection{Study design and vaccine efficacy - clinical signs, viremia, weight gain, and lung pathology.}

The study was conducted as depicted in Figure 1. Upon PRRSV inoculation, pigs displayed mild PRRSV symptoms beginning within 3-4 days of infection - fever (mainly at 1 wpi, data not shown, d.n.s.), lethargy, reduced food consumption, mild coughing / sneezing. No significant differences were observed for these symptoms; and they persisted to varying degrees until necropsy. Figure 2 illustrates viremia, weekly body weight gains as well as gross- and histopathology scores.

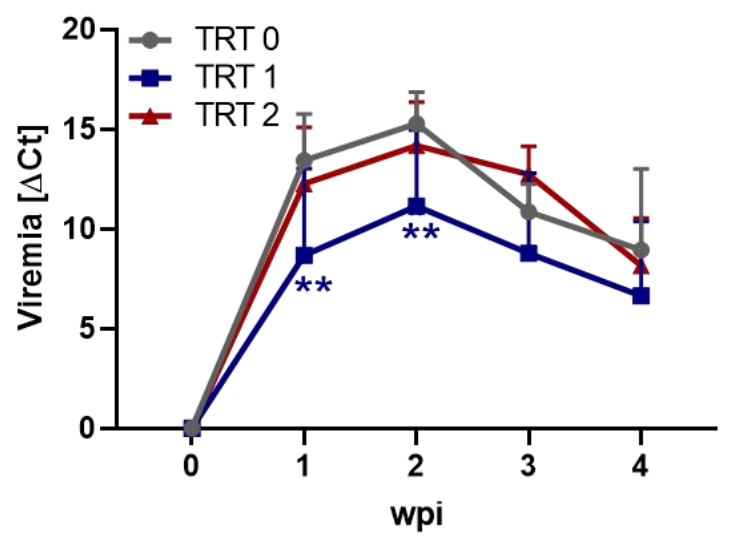

B

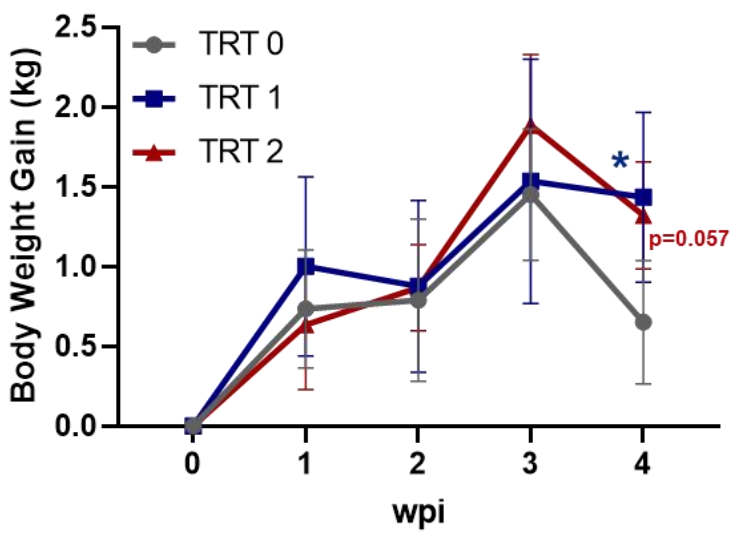

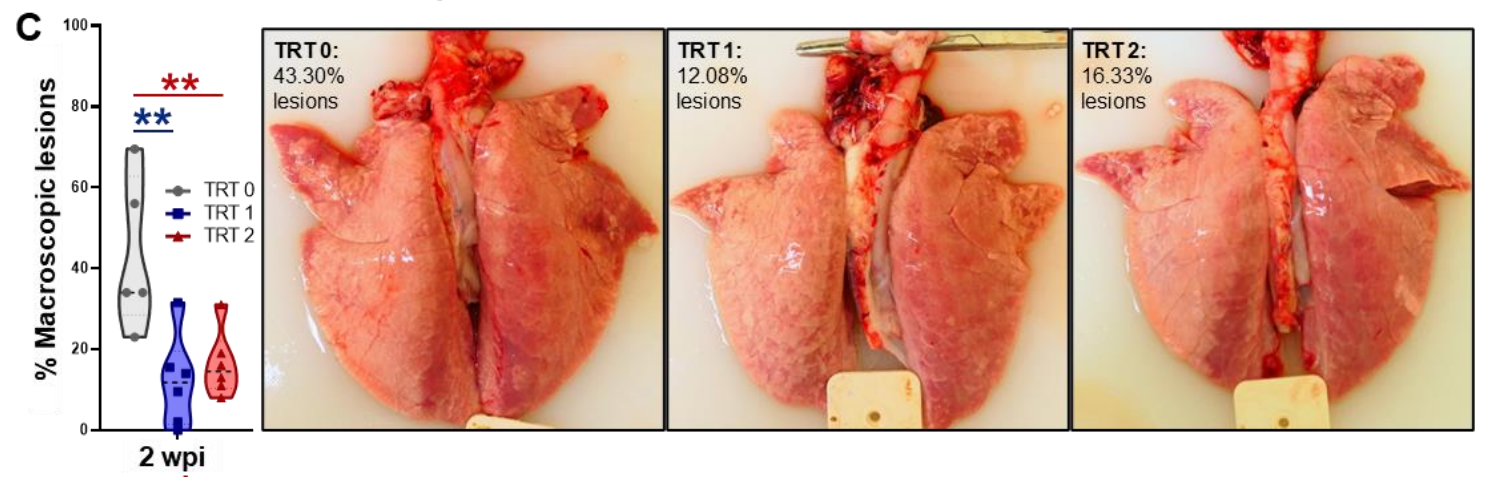

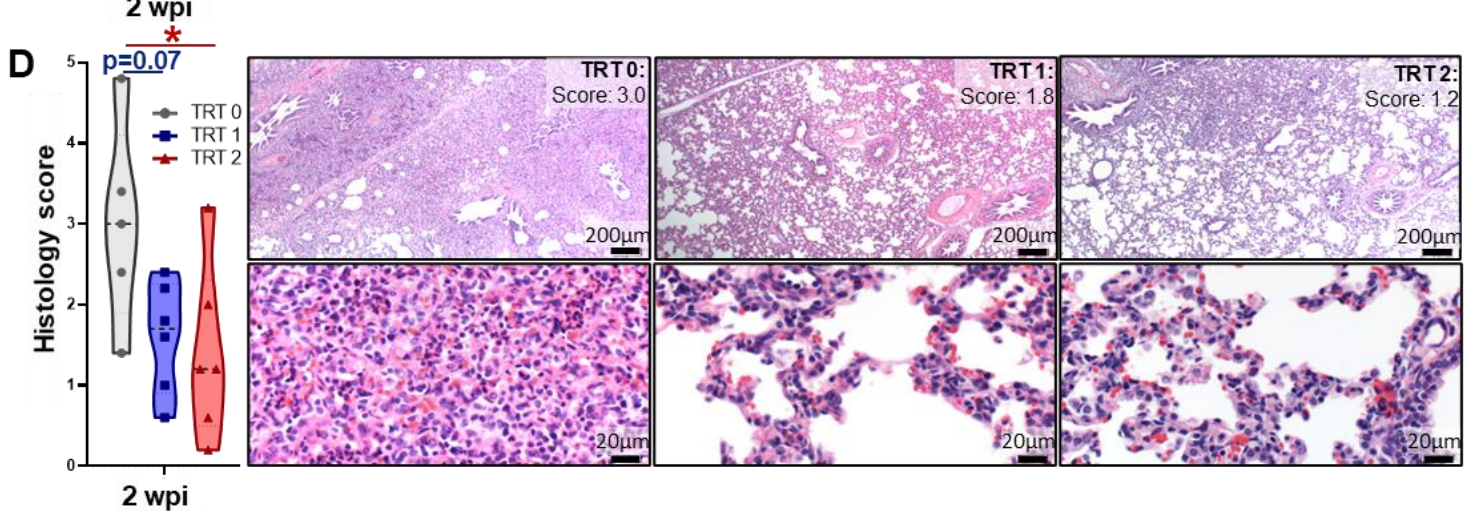

Figure 2. Maternal AIV vaccination boost immunity to PRRSV-2 in 2-week old piglets: Viremia (A) and weekly body weight gains (B) were analyzed at different weeks post inoculation (wpi). For both, data were analyzed by mixed-effects model (REML) with Dunnett's multiple comparisons test. (C) Percentage of macroscopic lung lesions, and (D) lung interstitial pneumonia histology scores at 2 weeks post inoculation. Data in (C) and (D) were analyzed by 1-way ANOVA with Dunnett's multiple comparison. All differences are shown within time point and between treatments ${ }^{* *} p<0.01$ and ${ }^{*} p<0.05$. 
As shown in Figure 2A, all pigs were PRRSV-2 negative at weaning and intranasal inoculation with PRRSV-2 induced a viremia that peaked at 2 wpi. While there was no difference in viremia between TRT 0 and TRT 2, TRT 1 had in the first two weeks significantly lower viremia than the control group TRT 0 . The weight gains of pigs in all groups was very similar for the first three weeks; yet, at the end of study and compared to TRT 0, TRT 2 had by number and TRT 1 a significantly higher weekly weight gain - Figure 2B. Most notably, while lung pathology is generally resolved in PRRSV infection and was therefore similar between groups at 4 wpi (d.n.s.), both maternal AIV vaccinations, so TRT $1+2$, significantly reduced the lung pathology at 2 wpi (Figure $2 C+D)$. Macroscopic lung lesions in lungs from TRT 0 were between $20-70 \%$; in contrast most pigs in TRT $1+2$ had lung lesions below $20 \%$ - Figure 2C. Similarly, while the median histopathology score in lungs from TRT 0 pigs was at three, it was at 1.8 for TRT 1 and 1.2 for TRT 2, respectively demonstrating a tendency to significance $(\mathrm{p}=0.07)$ and significant decrease in lung histopathology in pigs from AIV vaccinated sows - Figure 2D. These data demonstrate that AIV vaccination can significantly reduce viremia and lung pathology; they also show that maternal AIV vaccination against PRRSV-2 can boost the immunity of 2-week old piglets.

\subsection{Induction of maternal neutralizing antibodies and their transfer to piglets.}

The induction of a humoral immune response in gilts and their offspring was analyzed by determining NA FFN titers (Figure 3).
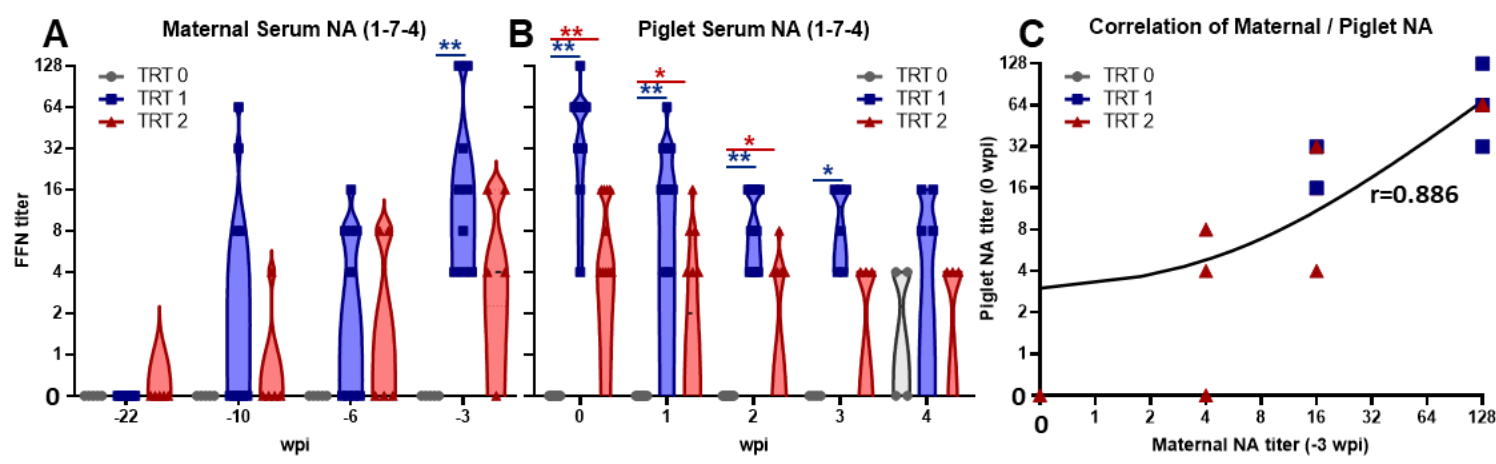

Figure 3. Autogenous inactivated boost vaccinations induce homologous neutralizing antibodies that are transferred to piglets. (A) Maternal serum NA titers to the homologous 1-7-4 strain after vaccination. (B) Piglet serum NA titers to 1-7-4 prior to inoculation (0 weeks post inoculation, wpi) and weekly after inoculation. (C) Pearson correlation matrix for maternal and piglet NA titers to 1-7-4 at -3 and 0 wpi, respectively. Data were analyzed via repeated-measures 2-way ANOVA with Dunnett's multiple comparisons. Significant differences are shown between treatments and within time point; they are designated as ${ }^{* *} p<0.01$ and ${ }^{*} p<0.05$.

Vaccination of all groups with the MLV induced NA titers in gilts between 4 and 64 with no significant differences between the three groups (d.n.s.). In contrast, while MLV vaccination alone (TRT 0) did not include NAs against the heterologous 1-7-4 strain, both AIV boost vaccinations induced NA titers of up to 1:16 (for TRT 2) and even 1:128 (for TRT 1) - Figure 3A. These serum NAs were maternally transferred to piglets (Figure 3B): While TRT 0 piglets showed no NA titers at 0 wpi, TRT 1 and TRT 2 piglets possessed serum NAs to strain 1-7-4 prior to infection which directly correlated with maternal NA levels (Figure 3C, $r=0.886, p<0.0001$ ). These NA titers decreased over the first two weeks before stabilizing by 4 wpi. Yet, compared to TRT 0 , piglets from AIV-vaccinated sows (TRT 1+2) had significantly higher serum NA titers already before challenge and these increased titers lasted until 2-3 wpi, so until 4-5 weeks of age - Figure 3B.

\subsection{The systemic cell-mediated immune response to PRRSV.}

The systemic cell-mediated immune response to the 1-7-4 PRRSV strain was analyzed by studying the IFN- $\gamma$ production of lymphocytes and the determination of the contributing immune cell subsets using multi-color flow cytometry (Figure 4). 


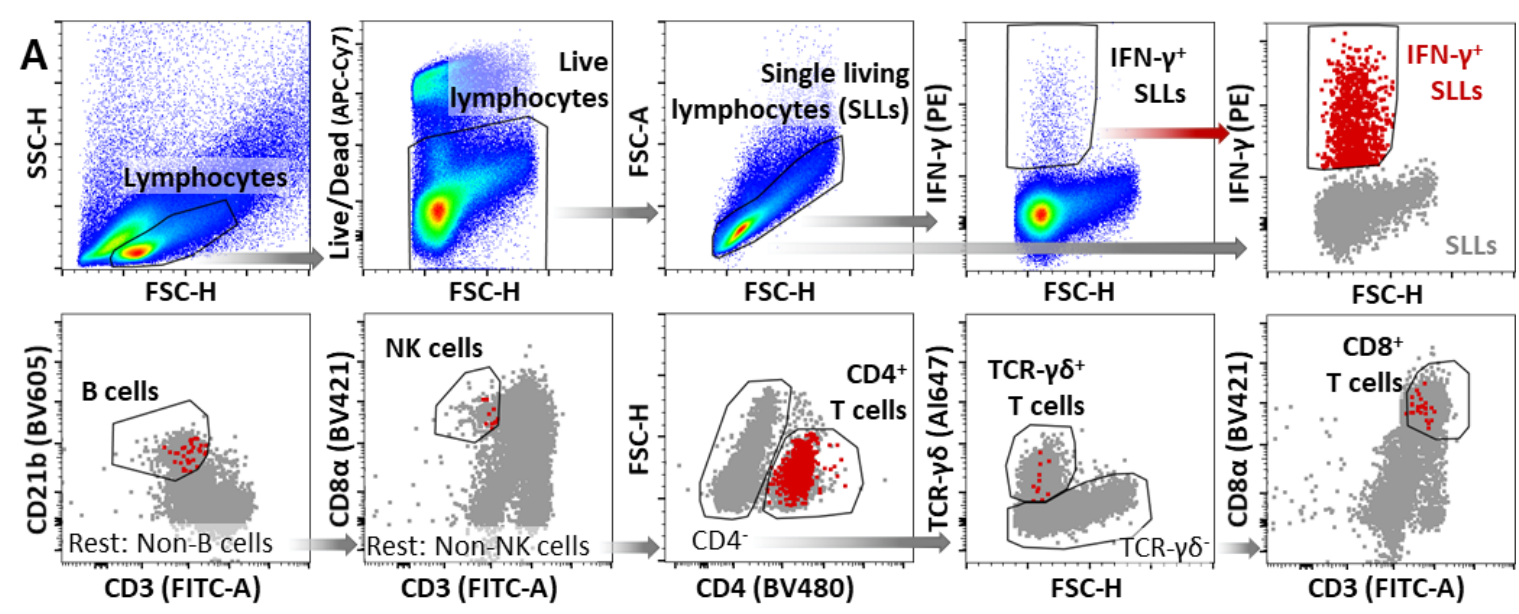

B
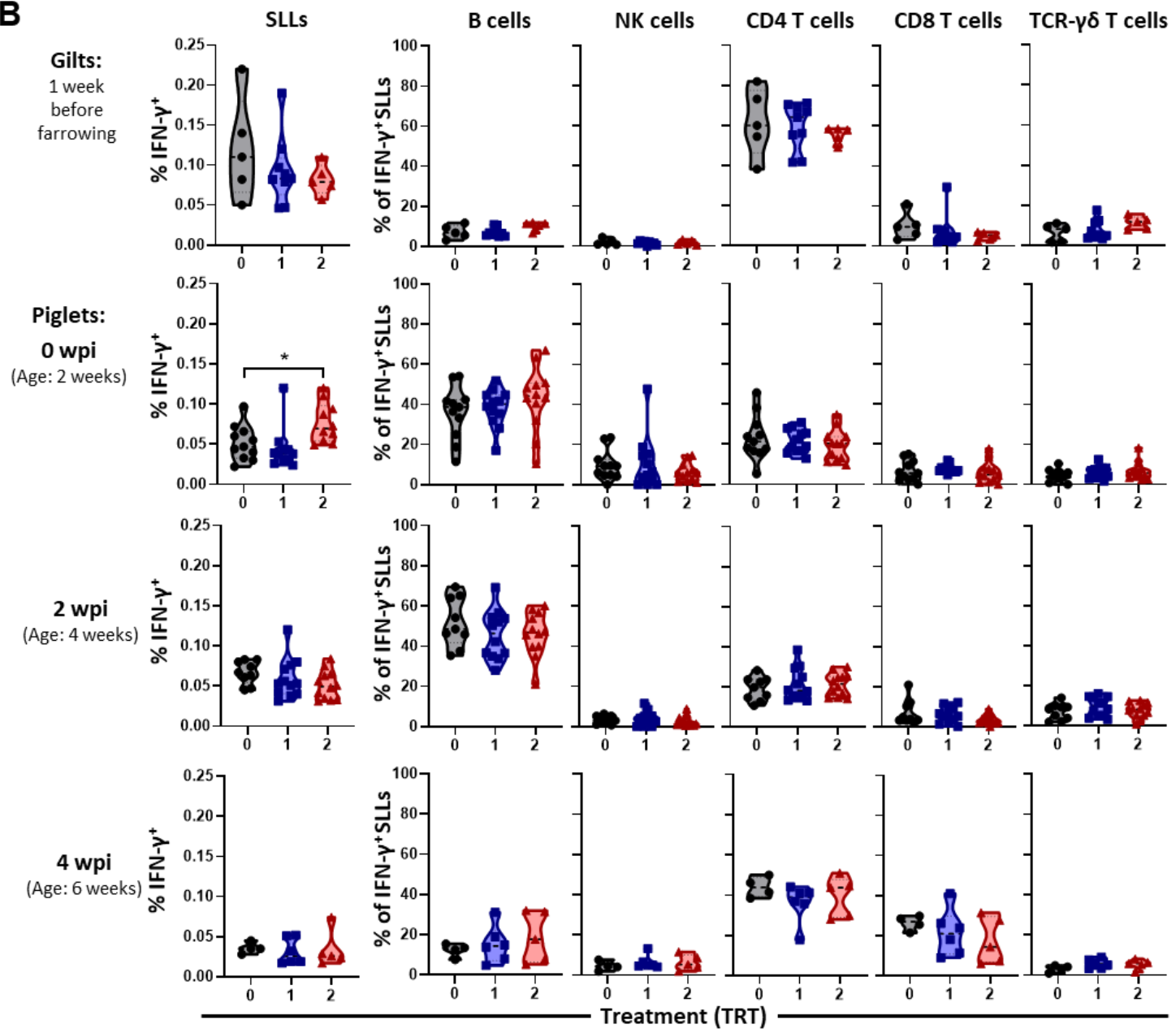

Figure 4: The systemic IFN- $\gamma$ response to PRRSV 1-7-4 in gilts and their offspring: (A) shows the gating hierarchy starting with a FSC/SSC gate on lymphocytes, the exclusion of dead cells and doublets to focus the analysis of IFN- $\gamma$ production on single living lymphocytes (SLLs). Subgates on B cells, NK cells, CD4, CD8 and TCR $-\gamma \delta \mathrm{T}$ cells were drawn on the whole SLL population (in grey) and overlaid by IFN- $\gamma$ producing cells (in red). (B) shows the IFN- $\gamma$ production as a percentage of all SLLs (left column) and the percentage of each immune cell subsets contributing to this IFN- $\gamma$ production (all other columns). Data were analyzed via 1-way ANOVA with Dunnett's multiple comparisons. Significant differences between treatments are designated as* $p<0.05$. 
Figure 4A shows the gating hierarchy. Figure 4B shows the IFN- $\gamma$ production in single living lymphocytes (SLLs) and the contribution of B cells, NK cells, CD4, CD8 and TCR- $\gamma \delta$ T cells to this production. At all time points, the systemic IFN- $\gamma$ response in SLLs was low with median frequencies ranging from $\sim 0.02 \%$ (mainly at $4 \mathrm{wpi}$ ) to $0.12 \%$ in gilts. Neither NK cells nor TCR- $\gamma \delta \mathrm{T}$ cells were responsible for more than $10 \%$ of the produced IFN- $\gamma$; consequently, B cells, and CD4 and CD8 T cells were the main contributors to the SLL IFN- $\gamma$ production.

In gilts, the vast majority of this IFN- $\gamma$ was produced by CD4 T cells. Nevertheless, analysis of the IFN- $\gamma$ in piglets before PRRSV inoculation showed that B cells were the main contributors to the systemic IFN- $\gamma$ production. At this time point, we also recorded the only significant increase in the percentage of IFN- $\gamma$ producing SLLs by one of the AIV vaccinations - TRT 2 . While the contribution of immune cells to this increased production did not reveal differences, IFN- $\gamma$ production within two immune cell subsets was significantly increased in this TRT 2 group as well - B cells and TCR- $\gamma \delta$ T cells (Supplementary Figure 2). Over the time course of PRRSV infection, the overall SLL IFN- $\gamma$ response slightly decline and the contributions of the different immune cell subsets shifted notably: The contribution of B cells dropped by more than half from over $40 \%$ to under $20 \%$, and the one of CD8 T cells increased from below $5 \%$ to $\sim 20 \%$. Yet, while CD4 T cells produced $\sim 20 \%$ of the total IFN- $\gamma$ at 0 and 2 wpi, with a contribution of over $40 \%$ they were the strongest IFN- $\gamma$ producing immune cell subset at 4 wpi.

\subsection{The differentiation and homing of IFN- $\gamma$ producing T-cell subsets in blood.}

Differentiation and homing of immune cells is critical for the vaccine-induced immunity. Differentiation into different memory cells can either speed up their development of an effector function (for TсмS) or provide them with an immediate effector function (for TeMs). Location is also critical to ensure a fast and directed response to a pathogen response: While Tcms home to secondary lymphoid tissues where they can undergo rapid proliferation, TEMs home to peripheral tissues to exert their effector function. Based on this relevance, we studied the differentiation and homing patterns of the IFN- $\gamma$ producing CD4, CD8 and TCR- $\gamma \delta$ T-cell subsets. These patterns are shown in Figure 5.

In gilts, over $80 \%$ of the systemic IFN- $\gamma$ producing CD4 T cells belong to the CD $8 \alpha^{+}$memory subsets - TCмS produce over $50 \%$ and Tемs $20-30 \%$. In contrast, in pre-inoculated piglets at $0 \mathrm{wpi}$, the vast majority of IFN- $\gamma$ within CD4 T cells is produced by naïve T cells $-\sim 80 \%$. Upon challenge, the role of naïve CD4 T cells decreases and memory T cells start to increase - at 2 wpi Tcms, and then at 4 wpi also TEMS (Figure 5B, "CD4+ ${ }^{+}$T cells" panels). IFN- $\gamma$ in gilt CD8 $\mathrm{T}$ cells is produced by $60 \% \mathrm{CCR}^{+}$and $40 \%$ CCR7- cells. In piglets, homing of IFN- $\gamma$ CD8 T cells was harder to assess based on their low frequency of IFN- $\gamma$ production. This is also reflected in the higher variance of these frequencies. In general, pre and 2 wpi, IFN- $\gamma$ was mainly produced by CCR7 ${ }^{+}$cells; in contrast, at 4 wpi, CCR7- CD8 $\mathrm{T}$ cells were the main IFN- $\gamma$ producers (Figure $5 \mathrm{~B}$, “CD8 T cells" panels).

As described in the literature, porcine TCR- $\gamma \delta \mathrm{T}$ cells possess a homing pattern that is inverse to their CD4 and CD8 TCR- $\alpha \beta$ counterparts: While naïve TCR- $\alpha \beta$ T cells express CCR7 and home to secondary lymphoid tissues, naïve TCR- $\gamma \delta \mathrm{T}$ cells do not express CCR7 and home to peripheral tissues [13]. In gilts, systemic IFN- $\gamma$ was produced by $\sim 20-50 \%$ of naïve CCR7-CD8 $\alpha$ - cells, and to $\sim 30-$ $60 \%$ by CCR7-CD $8 \alpha^{+}$tissue-homing, antigen experienced TCR- $\gamma \delta$ T cells; only a minority (mainly $0-$ $10 \%)$ was produced by CCR7 $+{ }^{+} \mathrm{CD} 8 \alpha^{+}$lymph node homing, antigen experienced TCR- $\gamma \delta \mathrm{T}$ cells (Figure 5B, "TCR- $\gamma \delta$ T cells" panels). As for CD8 T cells, the low frequency in IFN- $\gamma$ producing TCR$\gamma \delta \mathrm{T}$ cells in piglets led to high variabilities in their differentiation and homing patterns. Yet, one general conclusion can be drawn: Conversely to gilts, IFN- $\gamma$ in piglet TCR- $\gamma \delta$ T cells was mainly produced by naïve CCR7-CD8 $\alpha$ - TCR- $\gamma \delta$ T cells. 

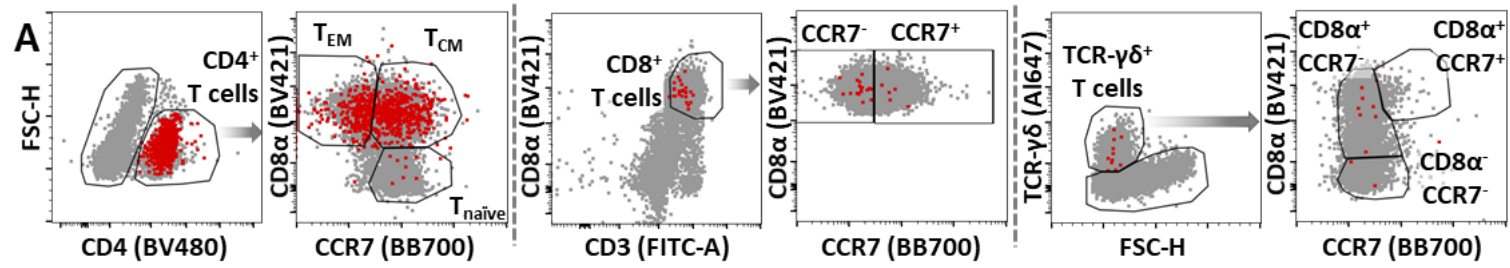

B
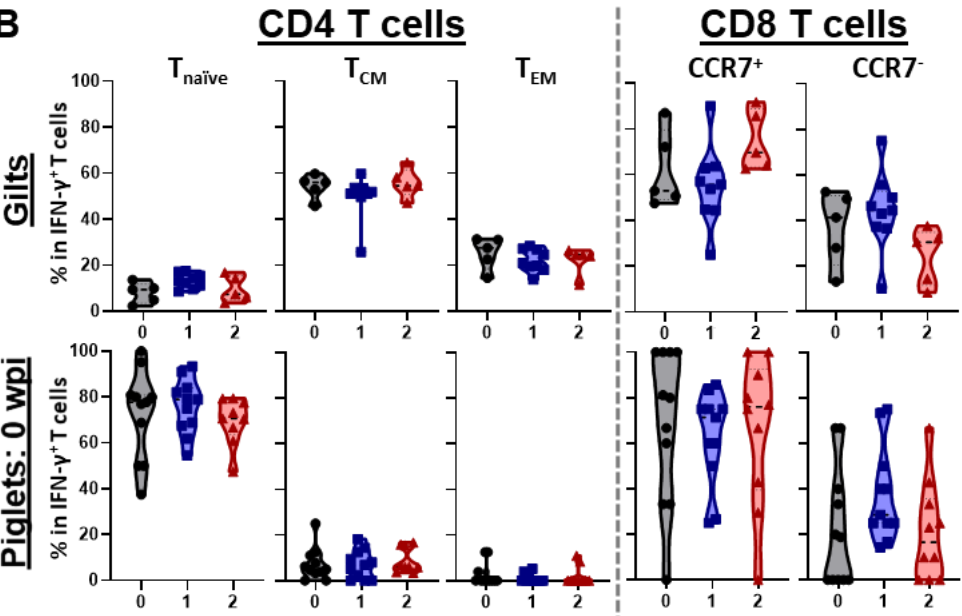

TCR-yó T cells

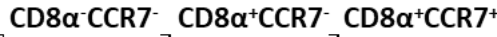
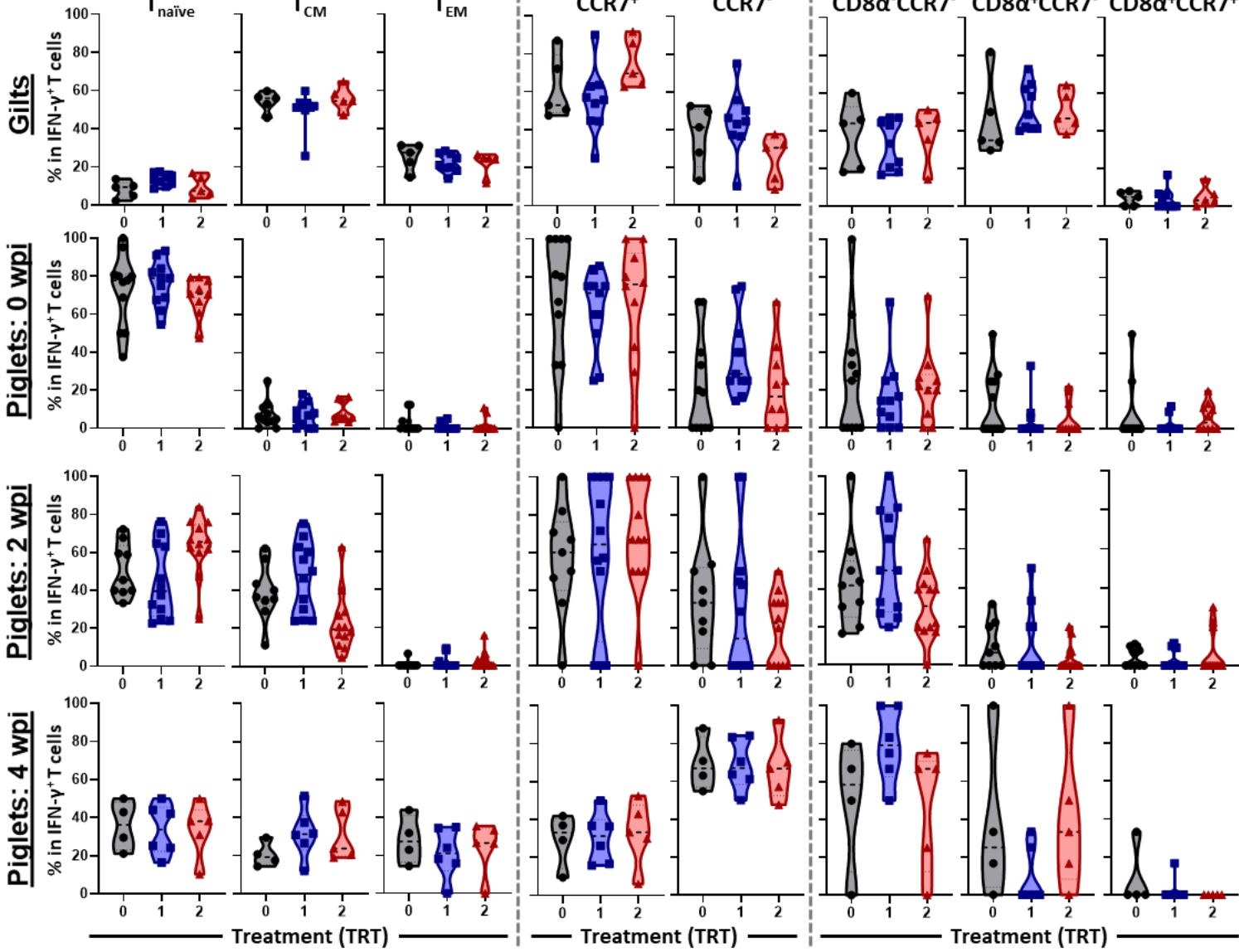

Figure 5: Differentiation of IFN- $\gamma^{+}$T-cell subsets in blood: (A) shows the gating used to differentiate CD4 naïve

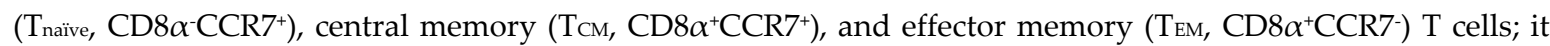
also shows the distinction of CCR7 ${ }^{+}$lymph node homing and CCR7- peripheral tissue homing CD8 T cells; and it illustrates the different TCR- $\gamma \delta$ T-cell subsets - naïve CD8 $\alpha^{-C C R 7} 7^{-}$, and antigen experienced CD8 $\alpha^{+}$CCR7- and CD8 $\alpha^{+}$CCR7 ${ }^{+}$cells. (B) shows the frequencies of these differentiation and homing defined subsets within IFN- $\gamma$ producing CD4 T cells (left), CD8 T cells (middle), and TCR- $\gamma \delta \mathrm{T}$ cells (right) in gilts at one week before farrowing (upper row), piglets at 0 wpi ( $2^{\text {nd }}$ row), 2 wpi ( $3^{\text {rd }}$ row) and 4 wpi $\left(4^{\text {th }}\right.$ row). Data were analyzed via 1-way ANOVA with Dunnett's multiple comparisons. No significant differences $(p<0.05)$ between groups were observed.

\subsection{The local cell-mediated immune response to PRRSV-BAL, lung, and tracheobronchial lymph nodes.}

While the systemic CMI response was studied in gilts and piglets throughout the challenge study, the local CMI response was studied at necropsy at 2 and 4 wpi as shown in Figures 6A and 6B. 

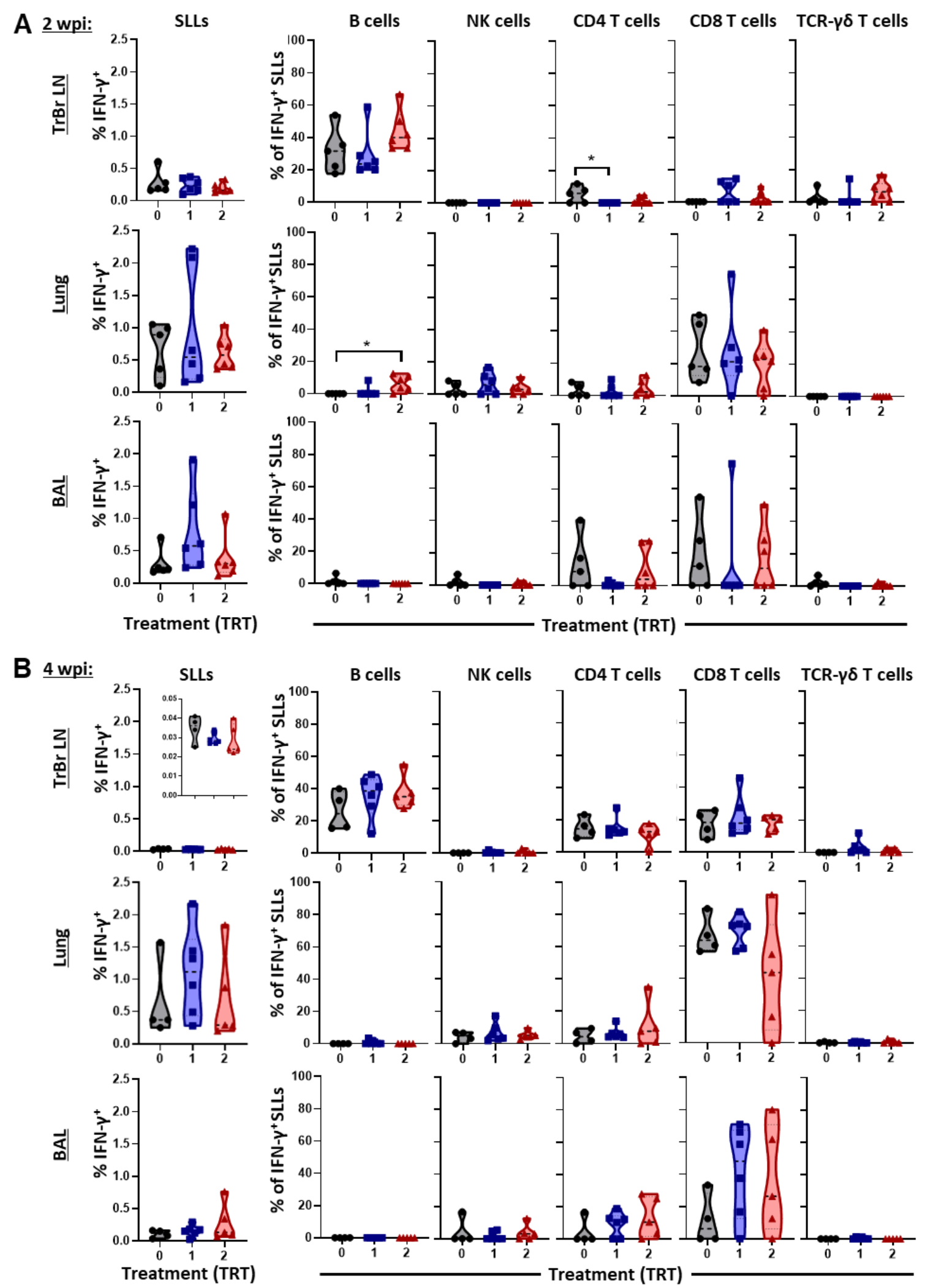

Figure 6: The local IFN- $\gamma$ response to PRRSV 1-7-4 in bronchoalveolar lavage, lungs, and tracheobronchial lymph nodes of piglets. IFN- $\gamma$ production as a percentage of all SLLs (left column) and the percentage of each immune cell subsets contributing to this IFN- $\gamma$ production (all other columns) is shown within tracheobronchial lymph nodes ( $\operatorname{TrBr} \mathrm{LN})$, lung tissue, and bronchoalveolar lavage (BAL) at 2 wpi (A) and 4 wpi (B). Data were analyzed via 1-way ANOVA with Dunnett's multiple comparisons. Significant differences between treatments are designated as ${ }^{*} p<0.05$. 
At 2 wpi, no differences between groups were observed for the overall IFN- $\gamma$ production within SLLs; this production was with $0.1-0.5 \%$ lower in the TrBr LNs than in the lung and BAL (each $~ 0.2-2 \%$ ). For the TrBr LNs, B cells were the major producer of IFN- $\gamma$ at this time point. B cells from TRT 2 showed a higher contribution to this IFN- $\gamma$ production by number in TrBr LNs and significantly in lung tissue. Yet, CD8 T cells were the major contributor to the IFN- $\gamma$ production in the lung and they share this spot with CD4 T cells in the BAL.

At 4 wpi, IFN- $\gamma$ production in TrBr LNs was very low. B cells were still the main contributors but CD4 and CD8 T cells now also provide $\sim 20 \%$ each of the produced IFN- $\gamma$. In lung tissue and BAL, CD8 $\mathrm{T}$ cells could expand their role in IFN- $\gamma$ production by often producing $20-80 \%$ of the overall IFN $-\gamma$. While B cells and TCR- $\gamma \delta$ T cells nearly show no IFN- $\gamma$ production, NK cells and CD4 T cells also produced some IFN- $\gamma$ up to $\sim 10 \%$ and $25 \%$, respectively.

These data show that B cells are mainly producing IFN- $\gamma$ in TrBr LNs and that CD8 T cells are the main IFN- $\gamma$ producers in lung tissue and BAL.

3.6. The differentiation and homing of IFN- $\gamma$ producing T-cell subsets in BAL, lung, and tracheobronchial lymph nodes.

As systemically, the differentiation and homing patterns of CD4, CD8, and TCR- $\gamma \delta \mathrm{T}$ cell subsets was analyzed by their CD8 $\alpha$ and CCR7 expression (Figure 7).

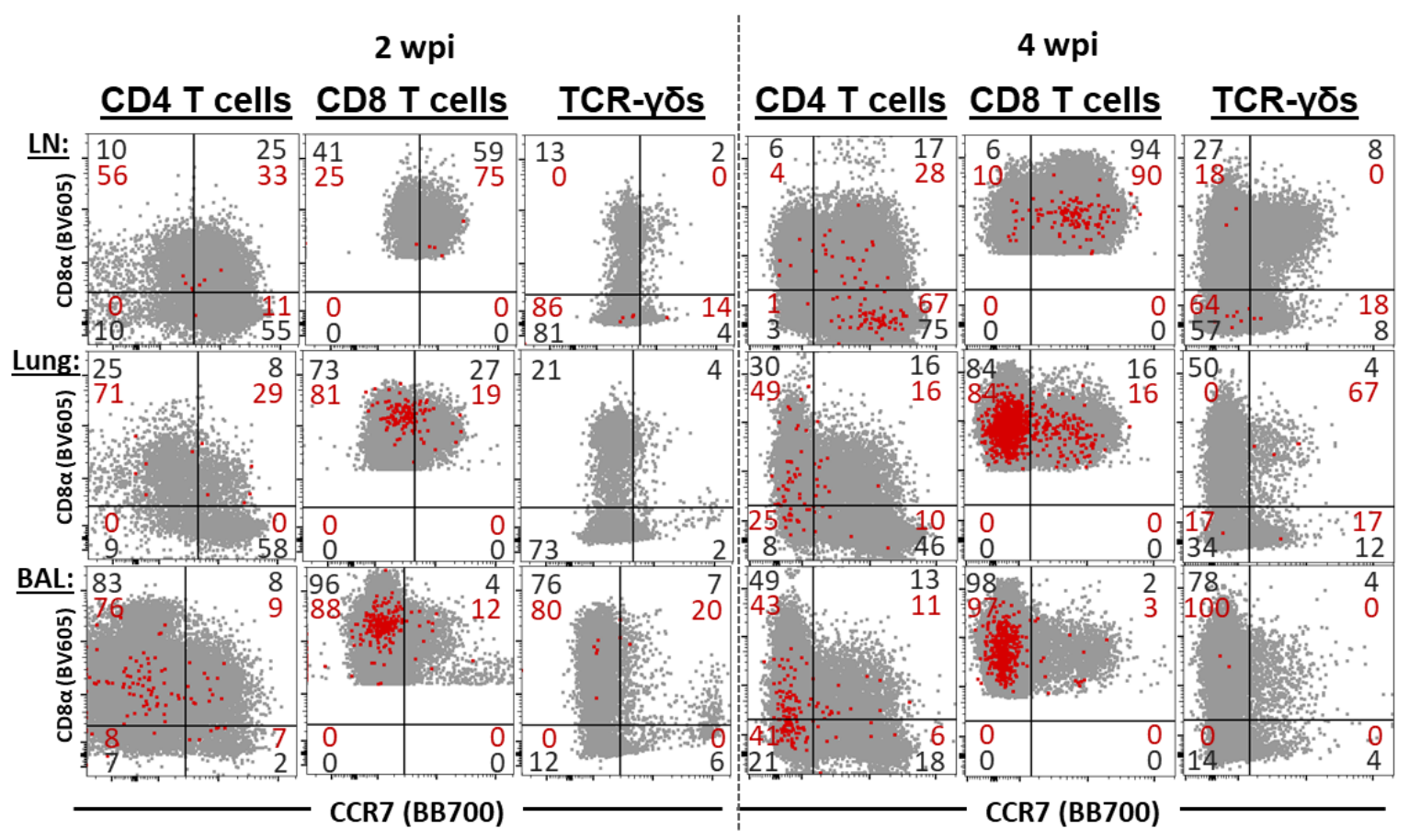

Figure 7: Differentiation of IFN- $\gamma^{+}$T-cell subsets in tracheobronchial lymph nodes, lung tissue and bronchoalveolar lavage (BAL): These overlays show the CCR7 (x-axis) and CD8 $\alpha$ (y-axis) expression of CD4, CD8, and TCR- $\gamma \delta$ T-cell subsets (grey) or the respective IFN- $\gamma^{+}$T-cell subsets (red) from all animals in tracheobronchial lymph nodes (LN), lung tissue, and BAL at 2 wpi (three left columns) and 4 wpi (three right columns). No statistical analysis was performed.

While the low frequencies of IFN- $\gamma^{+}$cells limits the analysis of the differentiation of TCR- $\gamma \delta$ T cells and at 2 wpi, also of CD4 T cells, these analyses provided a valuable insight into the differentiation of CD4 T cells at 4 wpi and of CD8 T cells at both 2 and 4 wpi. As expected, the majority these cells in $\mathrm{TrBr}$ LNs express the lymphoid tissue homing marker CCR7. In contrast, both the majority of IFN- $\gamma^{+}$CD4 and CD8 T cells are CCR7- in lungs and BAL.

At 4 wpi, IFN- $\gamma^{+}$CD4 T cells show a remarkable difference in their CD8 $\alpha$ and CCR7 expression: Even at 4 wpi, IFN- $\gamma^{+}$CD4 $\mathrm{T}$ cells in TrBr LNs mainly belong to CD8 $\alpha$-CCR7 ${ }^{+}$naïve T cells; in a strong contrast, about half of the IFN- $\gamma^{+}$CD4 T cells in lungs and BAL are CD $8 \alpha^{+}$CCR7- TEM cells; even more 
remarkable is that $25 \%$ (lung) and $42 \%$ (BAL) of these cells IFN- $\gamma^{+}$CD4 T cells are CD8 $\alpha$-CCR7- - an immune phenotype that has not yet been described in pigs.

\section{Discussion}

The purpose of the present study was to answer the questions i) if and ii) how AIV vaccinations (TRT 1+2) can boost an industry standard gilt MLV vaccination (TRT 0) to better protect their offspring from early PRRSV challenge. The metrics to answer the first question, the question of vaccine efficacy, was a challenge study in 2-week old piglets with the main assessments being viremia and lung pathology. To answer the second question, the question of vaccine immunogenicity, we included a detailed analysis of the vaccine induced humoral and CMI response in gilts and piglets.

Based on our main goal, this study did not include non-vaccinated gilts and non-challenged piglets. Yet, we can anticipate the following results within these groups based on the literature: i) gilt vaccination can result in transfer of maternal immune cells $[8,24]$ and IFN- $\gamma$ secreting cells; ii) antiPRRSV maternal-derived antibodies in unchallenged piglets would have remained over the course of the four-week study [25, 26]; iii) PRRSV-2 infection in piglets from unvaccinated gilts would have been more severe than in our treatments due to lack of maternal-derived antibodies and CMI transfer $[13,26,27]$.

Vaccine efficacy analysis between our treatment groups clearly showed that our maternal AIV boost vaccination strategy (Figure 1) was able to at least partially protect the offspring: TRT 1 significantly decreased viremia and improved the piglet weight gain towards the end of the study; in addition, both TRT 1+2 significantly decreased lung pathology (Figure 2). This is in line with a previous study on maternal boost vaccinations using either MLV or AIV against a PRRSV-1 strain: While both booster vaccinations increased the farm-specific NA titers in the sows, only the AIV provided the highest NA titers to offspring and was detectable for five weeks after birth; yet, both vaccinated groups had lower viremia upon PRRSV exposure in nursery than offspring from unvaccinated sows [26]. Combined, these data demonstrate that maternal AIV boost vaccinations can represent an efficient tool to limit the effect of both PRRSV-1\&2 on pre-weaning piglets.

Vaccine immunogenicity analysis showed a clear effect of the AIV vaccinations on the humoral immune response in both gilts and piglets (Figure $3 \mathbf{A}+\mathbf{B}$ ): While MLV vaccination alone (TRT 0) did not induce NAs against the 1-7-4 challenge strain, both AIV boost vaccinations (TRT 1+2) induced considerable NA titers in most (TRT 2) or even all (TRT 1) gilts. Of note, with a correlation coefficient of $\mathrm{r}=0.886$ and $p<0.0001$ these NA were strongly transferred to their offspring (Figure 3C). This strong correlation between maternal and offspring NA titers at weaning is consistent with previous research $[25,28]$. In most of these piglets, NA could be detected in serum until $4 \mathrm{wpi}$; at that time some of the TRT 0 piglets developed their own NA. As mentioned above, this timeline supports previous studies showing that maternal derived antibodies can stay in piglets for 4 weeks $[25,26]$.

Combined with the vaccine efficacy data, these NA data demonstrate three main conclusions: i) Maternal AIV vaccination can efficiently boost the NA levels against their homologous PRRSV strain not only in the gilts but also in their offspring; ii) these NA levels stay high in young piglets until or even after weaning age ( 2-3 wpi); and iii) our results indicate that this AIV-boost induced NAs at least partially protected these early weaners from challenge with the autogenous PRRSV strain at 2 weeks of age. These data support previous studies showing protection by NAs through two passive transfer experiments to be protective in pregnant sows [29] and partially protective in young weaned pigs [30]. Yet, follow-on studies by Osorio and others have examined the difficulty of achieving NAs through vaccination that provide subsequent challenge protection against homologous and heterologous PRRSV strains in nursery pigs [31-35] and in gestational gilts / sows [36-39]. These studies are often strain and age dependent; but in general they reveal the following: Generation of serum NAs is delayed against PRRSV and titers are lower than in other common swine disease vaccinations; and cross-reactivity against heterologous PRRSV strains is limited. Based on these limitations, it seems crucial to use an optimized maternal vaccination regimen such as an MLV prime / AIV boost combination to provide the best protection for piglets. 
Compared to the humoral immune response, vaccine immunogenicity analysis of the CMI response showed a much lower difference between the treatment groups. This can be explained in one of two ways: Either AIV did induce NAs but not a CMI response against the 1-7-4 strain, or the MLV-induced CMI response alone was already cross-reactive and the AIV boost effect was limited. While we cannot rule out either of these two options, our own (partially yet unpublished) results and the literature support the latter option: While NA titers often react only to homologous PRRSV strains, the CMI response exhibits greater cross-reactivity between heterologous PRRSV strains [[13] combined with yet unpublished results showing limited cross-reactivity between heterologous PRRSV strains; and [31]].

The most striking difference in the CMI response between the treatment groups was that at 0 wpi, pigs in TRT 2 had a higher systemic IFN- $\gamma$ response in lymphocytes (Figure 4); and this increase was based on a stronger IFN- $\gamma$ response in B cells and TCR- $\gamma \delta$ T cells (Supplementary Figure 2). At 2 wpi, B cells still had a higher IFN- $\gamma$ response by number in the $\operatorname{TrBr} \mathrm{LN}$ and significantly in the lung; and while TCR- $\gamma \delta$ T cells did not show a response in the lung, by number their IFN- $\gamma$ response was also higher in $\operatorname{TrBr}$ LNs (Figure 6). These data indicate that AIV vaccination not only has the potential to boost a NA response, but it can also boost the CMI response via IFN- $\gamma$ producing $B$ cells and TCR- $\gamma \delta$ T cells.

Different types of IFN- $\gamma$ producing B cells have been reported in mice. "B effector 1" cells produced IFN- $\gamma$ in response to IL-12 and IL-18 stimulation; this response was dependent on IFN- $\gamma$ receptor and the T-box transcription factor T-bet [40]. In addition, Bao et al. reported an inducible CD11a ${ }^{\text {hi Fc }} \gamma$ RIII hi B-cell population that they called "innate B cells"; in contrast to conventional B cells, upon CD40 ligation these innate B cells produced high amounts of IFN- $\gamma$ [41]. Rodríguez-Carreño et al. studied IFN- $\gamma$ producing cells by flow cytometry [42]: They did not find IFN- $\gamma$ producing B cells in 6-month and 3-year old pigs after stimulation with PMA/ ionomycin. This discrepancy can be mainly explained by the very low frequency of IFN- $\gamma$ producing B cells in older pigs and the data acquisition used by Rodríguez-Carreño et al.: In our gilts, $<0.1 \%$ of B cells produced IFN- $\gamma$ (d.n.s); while Rodríguez-Carreño et al. did not state the number of recorded cells, the figure allows to estimate that the recorded B cell number is $<1,000$ with a background of $\sim 30$ cells in the IFN- $\gamma^{+}$B-cell gate; hence, IFN- $\gamma$ production by B cells at a rate of $<0.1 \%$ would be reflected at less than one IFN- $\gamma^{+}$ B-cell in their system; and therefore, it could have not been detected in their system (Figure 2a of [42]). While IFN- $\gamma$ producing B cells have not been described yet in pigs, Ogawa et al. showed in 2016 that compared to colostrum-deprived piglets, colostrum-fed piglets had significantly higher blood B cells numbers [7]. This demonstrates the successful transfer of B cells from sows to their offspring. Our data showing that B cells both in blood and TrBr LNs produce IFN- $\gamma$ provides an indication that these B cells not only contribute to a future antibody production, but they could also induce isotype class-switching from IgM to IgG [43]. Taken together, these data suggest an important role of IFN- $\gamma$ producing B cells in the protection of young piglets; and future studies on maternal transfer of immunity from sows to piglets should enclose a detailed analysis of B cells including these IFN- $\gamma$ producing B cells.

Regarding the role of TCR- $\gamma \delta$ T cells in early protection of piglets, Bandrick et al. showed in 2014 that TCR- $\gamma \delta$ T cells are the main T-cell subset in sow colostrum; and these cells also showed the strongest increase in piglets between pre- and after suckling [8]. This shows that these TCR- $\gamma \delta \mathrm{T}$ cells are highly transferred between sow and piglet; and together with our data, both studies support a role of TCR- $\gamma \delta \mathrm{T}$ cells in the protection of piglets at the very early stages of life.

While the IFN- $\gamma$ production by B-cells and TCR- $\gamma \delta$ T-cells was the only difference between the treatment groups, the detailed analysis of the CMI response revealed additional very interesting patterns of the anti-PRRSV response within the different locations and age groups. In lung tissue and BAL, CD8 T cells were consistently the strongest IFN- $\gamma$ producers at necropsy, which was performed 2 and 4 wpi, so at 4 and 6 weeks of age. This is in line with our previous report in which we showed that CD8 T cells were the main lymphocyte subset in the lungs of PRRSV vaccinated or infected pigs at 9 wpi, or 13 weeks of age [13]. In addition to CD8 T cells, CD4 T cells also contributed to the local IFN- $\gamma$ production in lung tissue and BAL. While the expression of the homing marker CCR7 on both 
of these T cell subsets from lymphoid and peripheral tissue was unsurprising (mixed in blood, Figure 5; mainly CCR7 ${ }^{+}$in TrBrLN and mainly CCR7- in lung and BAL, Figure 7), the combined analysis of CD8 $\alpha$ and CCR7 in CD4 T cells from lung and BAL revealed an unexpected result: The presence of a novel CD4 T-cell subset in pigs - CD8 $\alpha$-CCR7- CD4 T cells (Figure 7).

As mentioned above, CD8 $\alpha$ and CCR7 are used in pigs to define three CD4 T cell subsets of increasing differentiation: $\mathrm{CD} 8 \alpha-\mathrm{CCR} 7^{+}$naïve, $\mathrm{CD} 8 \alpha-\mathrm{CCR} 7^{+} \mathrm{TCM}$ and $\mathrm{CD} 8 \alpha-\mathrm{CCR} 7^{+} \mathrm{TEM} \mathrm{CD} 4 \mathrm{~T}$ cells. The question is what stage of differentiation do these newly described CD $8 \alpha$-CCR7-CD4 T cells fall in? CCR7 is used in several species, but while CD8 $\alpha$ is the gold standard differentiation marker in porcine $T$ cells, CD45RA is used in humans to differentiate CD45RA+ naïve from CD45RA- memory cells. Sallusto et al. studied the CD45RA and CCR7 expression in human CD4 and CD8 T cells in peripheral blood [44]: Based on this CD45RA and CCR7 expression, they could identify three CD4: one naïve CD45RA ${ }^{+} \mathrm{CCR7}^{+}$, and two memory subsets, CD45RA-CCR7 ${ }^{+}$and CD45RA-CCR7-. They nicely demonstrated that while the CD45RA-CCR7 ${ }^{+}$cells expressed the lymph node homing marker only the CD45RA-CCR7- cells had an immediate effector function; and therefore, they named these cells Tсм and Tем cells, respectively. While Sallusto did not find CD45RA+CCR7- in CD4 T cells, they found them in CD8 $\mathrm{T}$ cells. So, these CD45RA ${ }^{+} \mathrm{CCR} 7-\mathrm{CD} 8$ cells represent the CD8 human counterpart to our newly described CD8 $\alpha$-CCR7- CD4 T cells in pigs. These human CD45RA+CCR7- CD8 T cells had a "particularly prominent expression of the CD8 effector molecule perforin; and this corresponded to a population of terminally differentiated CD27- effector T cells [45]; and these effector memory $\mathrm{T}$ cells re-expressing CD45RA were later termed TемRA cells [46]. In the meantime, these TEMRA cells have also been described for CD4 T cells; but their frequency is much lower than in human CD8 T cells and their role is less clear. These CD4 TEMRA cells are more frequent in patients with some viral infections such as dengue virus or cytomegalovirus; and they show a decreased CD27 expression but an increased expression of effector molecules [47]. Therefore, CD4 TEMRA cells seem to have a similar terminal differentiation and strong effector function as their CD8 counterparts. Based on these human studies, we hypothesize that these newly identified porcine CD8 $\alpha$-CCR7-CD4 T cells represent strong effectors and terminally differentiated CD4 TEMRA cells.

In contrast to BAL and lung tissue, in blood and secondary lymphoid tissue, B cells were the main producers of IFN- $\gamma$ until weaning age ( 0 and 2 wpi); their ongoing IFN- $\gamma$ production further justifies research into IFN- $\gamma$ producing B cells in young pigs. After weaning, so at 4 wpi, while B cells were still the main IFN- $\gamma$ producers in the TrBrLNs, CD4 T cells became the major source of IFN- $\gamma$ in blood. This trend seems to continue: In the older gilts, CD4 T cells were with $\sim 60 \%$ by far the strongest IFN- $\gamma$ producers. The important role of these CD4 $\mathrm{T}$ cells in the systemic response against both PRRSV-1 and -2 has been repeatedly shown for post-weaning animals [13, 48, 49].

As so often in research, while trying to solve the questions on if and how maternal AIV boost vaccinations can improve protection against PRRSV challenge in piglets, we shed light on an even more complex immune response than originally thought; and thereby, we simultaneously raised new questions not only on the role of CD8 $\alpha$-CCR7- CD4 T cells but especially on IFN- $\gamma$ producing B cells: i) "In addition to TCR- $\gamma \delta \mathrm{T}$ cells, why are mainly IFN- $\gamma$ producing B cells transferred from mother to offspring?"; ii) "How are these cells stimulated and which antigens do they recognize?"; iii) "Are they rather innate B cells or B effector 1 cells?"; iv) "What exact role do these IFN- $\gamma$ producing B cells play in the protection of young pigs?"; v) "What happens to these cells as the pig ages?". So, it seems that the orchestra playing the awe-inspiring symphony/ "harmonious complexity" of the maternalderived immunity just got a little bigger [1].

\section{Conclusions}

This study provides five main take home messages for the reader: 1) Maternal AIV boost vaccinations can improve the protection of pre-weaning piglets against the farm-prevalent PRRSV strain; 2) this protection is most likely based on a) the transfer of neutralizing antibodies and $b$ ) IFN- $\gamma$ producing B cells; 3) these IFN- $\gamma$ producing B cells are a major source of the systemic IFN- $\gamma$ response in early life of a piglet until the standard weaning age; 4) post-weaning, CD4 T cells are the major contributors of systemic IFN- $\gamma$; and 5) while CD8 T cells are the major responders against PRRSV in lung and 
BAL, CD4 T cells also contribute to this response, including a novel CD8 $\alpha$-CCR7- CD4 T-cell subset potentially representing porcine terminally differentiated CD4 TЕMRA cells.

Supplementary Materials: The following are available online at www.mdpi.com/xxx/s1, Figure S1: Flow cytometry gating hierarchy for studying the IFN $-\gamma$ response in BAL (shown), lung tissue, and tracheobronchial lymph nodes; Figure S2: The systemic IFN- $\gamma$ response to PRRSV 1-7-4 in piglets at 2 weeks of age ( 0 wpi).

Author Contributions: Conceptualization and validation, J.P., T.K., A.R.K., P.C.G. and Z.C.W.; methodology and investigation, J.P., T.K., A.R.K., Z.C.W., E.C., and P.C.G.; formal analysis, J.P., T.K., and A.R.K.,; resources, J.P. and T.K.; data curation, J.P., T.K. and A.R.K.; writing-original draft preparation, A.R.K.; writing-review and editing, A.R.K., Z.C.W., A.F.A., L.M.C., E.C., G.W.A., P.C.G, J.P., and T.K.; visualization, T.K. and A.R.K.; funding acquisition, supervision and project administration, J.P. and T.K.. All authors have read and agreed to the published version of the manuscript.

Funding: This research was funded by the Virginia Pork Council. A.R.K.'s graduate tuition and salary was provided by the United States Army.

Acknowledgments: We would like to thank Smithfield Foods for housing the gilt vaccine study and providing the piglets for the challenge study. We also thank the NC State Laboratory Animal Resources (LAR), especially Maria Stone, and the Central Procedures Laboratory (CPL), especially Lauren Buslinger, for their help with conducting the piglet challenge part. The NCSU CVM Swine Club supported the project for sampling and necropsy with Jamie Madigan and Sabra Bryant McCallister contributing significantly on these days.

Conflicts of Interest: "The authors declare no conflict of interest."

\section{References}

[1] Merriam-Webster Inc. The Merriam-Webster dictionary. Springfield, Massachusetts: Merriam-Webster, Incorporated; 2019.

[2] Butler JE, Wertz N, Sinkora M. Antibody Repertoire Development in Swine. Annu Rev Anim Biosci. 2017;5:255-79.

[3] Hurley WL, Theil PK. Perspectives on immunoglobulins in colostrum and milk. Nutrients. 2011;3:442-74.

[4] Jennewein MF, Abu-Raya B, Jiang Y, Alter G, Marchant A. Transfer of maternal immunity and programming of the newborn immune system. Semin Immunopathol. 2017;39:605-13.

[5] Poonsuk K, Zimmerman J. Historical and contemporary aspects of maternal immunity in swine. Anim Health Res Rev. 2018;19:31-45.

[6] Declerck I, Dewulf J, Sarrazin S, Maes D. Long-term effects of colostrum intake in piglet mortality and performance. J Anim Sci. 2016;94:1633-43.

[7] Ogawa S, Tsukahara T, Imaoka T, Nakanishi N, Ushida K, Inoue R. The effect of colostrum ingestion during the first 24 hours of life on early postnatal development of piglet immune systems. Anim Sci J. 2016;87:1511-5.

[8] Bandrick M, Ariza-Nieto C, Baidoo SK, Molitor TW. Colostral antibody-mediated and cell-mediated immunity contributes to innate and antigen-specific immunity in piglets. Developmental and comparative immunology. 2014;43:114-20.

[9] Gerner W, Käser T, Saalmüller A. Porcine T lymphocytes and NK cells--an update. Developmental and comparative immunology. 2009;33:310-20.

[10] Saalmüller A, Reddehase MJ, Bühring HJ, Jonjic S, Koszinowski UH. Simultaneous expression of CD4 and CD8 antigens by a substantial proportion of resting porcine T lymphocytes. Eur J Immunol. 1987;17:1297-301.

[11] Saalmüller A, Werner T, Fachinger V. T-helper cells from naive to committed. Vet Immunol Immunopathol. 2002;87:137-45.

[12] Reutner K, Leitner J, Müllebner A, Ladinig A, Essler SE, Duvigneau JC, et al. CD27 expression discriminates porcine $\mathrm{T}$ helper cells with functionally distinct properties. Vet Res. 2013;44:18. 
[13] Kick AR, Amaral AF, Cortes LM, Fogle JE, Crisci E, Almond GW, et al. The T-Cell Response to Type 2 Porcine Reproductive and Respiratory Syndrome Virus (PRRSV). Viruses. 2019;11.

[14] Holtkamp D.J. KJB, Neumann E.J., Zimmerman J.J., Rotto H., Yoder T.K., Wang C., Yeske P., Mowrer C. Haley C. Assessment of the economic impact of porcine reproductive and respiratory syndrome virus on United States pork producers. J Swine Health Prod. 2013;21:72-84.

[15] VanderWaal K, Deen J. Global trends in infectious diseases of swine. Proc Natl Acad Sci U S A. 2018;115:11495-500.

[16] Montaner-Tarbes S, Del Portillo HA, Montoya M, Fraile L. Key Gaps in the Knowledge of the Porcine Respiratory Reproductive Syndrome Virus (PRRSV). Front Vet Sci. 2019;6:38.

[17] Rahe MC, Murtaugh MP. Effector mechanisms of humoral immunity to porcine reproductive and respiratory syndrome virus. Vet Immunol Immunopathol. 2017;186:15-8.

[18] Loving CL, Osorio FA, Murtaugh MP, Zuckermann FA. Innate and adaptive immunity against Porcine Reproductive and Respiratory Syndrome Virus. Vet Immunol Immunopathol. 2015;167:1-14.

[19] Lunney JK, Fang Y, Ladinig A, Chen N, Li Y, Rowland B, et al. Porcine Reproductive and Respiratory Syndrome Virus (PRRSV): Pathogenesis and Interaction with the Immune System. Annu Rev Anim Biosci. 2016;4:129-54.

[20] Balka G, Dreckmann K, Papp G, Kraft C. Vaccination of piglets at 2 and 3 weeks of age with Ingelvac PRRSFLEX® EU provides protection against heterologous field challenge in the face of homologous maternally derived antibodies. Porcine Health Manag. 2016;2:24.

[21] Kraft C, Hennies R, Dreckmann K, Noguera M, Rathkjen PH, Gassel M, et al. Evaluation of PRRSv specific, maternally derived and induced immune response in Ingelvac PRRSFLEX EU vaccinated piglets in the presence of maternally transferred immunity. PLoS One. 2019;14:e0223060.

[22] Wu WH, Fang Y, Farwell R, Steffen-Bien M, Rowland RR, Christopher-Hennings J, et al. A 10-kDa structural protein of porcine reproductive and respiratory syndrome virus encoded by ORF2b. Virology. 2001;287:183-91.

[23] Halbur PG, Paul PS, Frey ML, Landgraf J, Eernisse K, Meng XJ, et al. Comparison of the pathogenicity of two US porcine reproductive and respiratory syndrome virus isolates with that of the Lelystad virus. Vet Pathol. 1995;32:648-60.

[24] Bandrick M, Pieters M, Pijoan C, Molitor TW. Passive transfer of maternal Mycoplasma hyopneumoniaespecific cellular immunity to piglets. Clin Vaccine Immunol. 2008;15:540-3.

[25] Houben S, van Reeth K, Pensaert MB. Pattern of infection with the porcine reproductive and respiratory syndrome virus on swine farms in Belgium. Zentralbl Veterinarmed B. 1995;42:209-15.

[26] Geldhof MF, Van Breedam W, De Jong E, Lopez Rodriguez A, Karniychuk UU, Vanhee M, et al. Antibody response and maternal immunity upon boosting PRRSV-immune sows with experimental farm-specific and commercial PRRSV vaccines. Vet Microbiol. 2013;167:260-71.

[27] Drigo M, Giacomini E, Lazzaro M, Pasotto D, Bilato D, Ruggeri J, et al. Comparative evaluation of immune responses of swine in PRRS-stable and unstable herds. Vet Immunol Immunopathol. 2018;200:32-9.

[28] Dvorak CMT, Payne BJ, Seate JL, Murtaugh MP. Effect of Maternal Antibody Transfer on Antibody Dynamics and Control of Porcine Circovirus Type 2 Infection in Offspring. Viral Immunol. 2018;31:40-6.

[29] Osorio FA, Galeota JA, Nelson E, Brodersen B, Doster A, Wills R, et al. Passive transfer of virus-specific antibodies confers protection against reproductive failure induced by a virulent strain of porcine reproductive and respiratory syndrome virus and establishes sterilizing immunity. Virology. 2002;302:9-20. 
[30] Lopez OJ, Oliveira MF, Garcia EA, Kwon BJ, Doster A, Osorio FA. Protection against porcine reproductive and respiratory syndrome virus (PRRSV) infection through passive transfer of PRRSV-neutralizing antibodies is dose dependent. Clin Vaccine Immunol. 2007;14:269-75.

[31] Correas I, Osorio FA, Steffen D, Pattnaik AK, Vu HL. Cross reactivity of immune responses to porcine reproductive and respiratory syndrome virus infection. Vaccine. 2017;35:782-8.

[32] Balasch M, Fort M, Taylor LP, Diaz I, Mateu E, Calvert JG. Immune response development after vaccination of 1-day-old naive pigs with a Porcine Reproductive and Respiratory Syndrome 1-based modified live virus vaccine. Porcine Health Manag. 2019;5:2.

[33] Jeong J, Choi K, Kang I, Park C, Chae C. Evaluation of a 20year old porcine reproductive and respiratory syndrome (PRRS) modified live vaccine (Ingelvac((R)) PRRS MLV) against two recent type 2 PRRS virus isolates in South Korea. Vet Microbiol. 2016;192:102-9.

[34] Park C, Baek JH, Cho SH, Jeong J, Chae C, You SH, et al. Field porcine reproductive and respiratory syndrome viruses (PRRSV) attenuated by codon pair deoptimization (CPD) in NSP1 protected pigs from heterologous challenge. Virology. 2020;540:172-83.

[35] Meier WA, Galeota J, Osorio FA, Husmann RJ, Schnitzlein WM, Zuckermann FA. Gradual development of the interferon-gamma response of swine to porcine reproductive and respiratory syndrome virus infection or vaccination. Virology. 2003;309:18-31.

[36] Yang S, Oh T, Cho H, Chae C. A comparison of commercial modified-live PRRSV-1 and PRRSV-2 vaccines against a dual heterologous PRRSV-1 and PRRSV-2 challenge in late term pregnancy gilts. Comp Immunol Microbiol Infect Dis. 2020;69:101423.

[37] Yang S, Oh T, Kang I, Park SJ, Chae C. Efficacy of concurrent vaccination with modified-live PRRSV-1 and PRRSV-2 vaccines against heterologous dual PRRSV-1 and PRRSV-2 challenge in late term pregnancy gilts. Vet Microbiol. 2019;239:108497.

[38] Jeong J, Kim S, Park KH, Kang I, Park SJ, Park C, et al. Evaluation of the effect of a porcine reproductive and respiratory syndrome (PRRS) modified-live virus vaccine on sow reproductive performance in endemic PRRS farms. Vet Microbiol. 2017;208:47-52.

[39] Han K, Seo HW, Park C, Chae C. Vaccination of sows against type 2 Porcine Reproductive and Respiratory Syndrome Virus (PRRSV) before artificial insemination protects against type 2 PRRSV challenge but does not protect against type 1 PRRSV challenge in late gestation. Vet Res. 2014;45:12.

[40] Harris DP, Goodrich S, Gerth AJ, Peng SL, Lund FE. Regulation of IFN-gamma production by B effector 1 cells: essential roles for T-bet and the IFN-gamma receptor. J Immunol. 2005;174:6781-90.

[41] Bao Y, Liu X, Han C, Xu S, Xie B, Zhang Q, et al. Identification of IFN-gamma-producing innate B cells. Cell Res. 2014;24:161-76.

[42] Rodriguez-Carreno MP, Lopez-Fuertes L, Revilla C, Ezquerra A, Alonso F, Dominguez J. Phenotypic characterization of porcine IFN-gamma-producing lymphocytes by flow cytometry. J Immunol Methods. 2002;259:171-9.

[43] Murphy K, Travers P, Walport M, Janeway C. Janeway's immunobiology. 7th ed. New York: Garland Science; 2008.

[44] Sallusto F, Lenig D, Forster R, Lipp M, Lanzavecchia A. Two subsets of memory T lymphocytes with distinct homing potentials and effector functions. Nature. 1999;401:708-12.

[45] Hamann D, Baars PA, Rep MH, Hooibrink B, Kerkhof-Garde SR, Klein MR, et al. Phenotypic and functional separation of memory and effector human CD8+ T cells. J Exp Med. 1997;186:1407-18. 
[46] Sallusto F, Geginat J, Lanzavecchia A. Central memory and effector memory T cell subsets: function, generation, and maintenance. Annu Rev Immunol. 2004;22:745-63.

[47] Tian Y, Babor M, Lane J, Schulten V, Patil VS, Seumois G, et al. Unique phenotypes and clonal expansions of human CD4 effector memory T cells re-expressing CD45RA. Nat Commun. 2017;8:1473.

[48] Mair KH, Koinig H, Gerner W, Hohne A, Bretthauer J, Kroll JJ, et al. Carbopol improves the early cellular immune responses induced by the modified-life vaccine Ingelvac PRRS(R) MLV. Vet Microbiol. 2015;176:352-7. [49] Park C, Seo HW, Han K, Kang I, Chae C. Evaluation of the efficacy of a new modified live porcine reproductive and respiratory syndrome virus (PRRSV) vaccine (Fostera PRRS) against heterologous PRRSV challenge. Vet Microbiol. 2014;172:432-42. 